
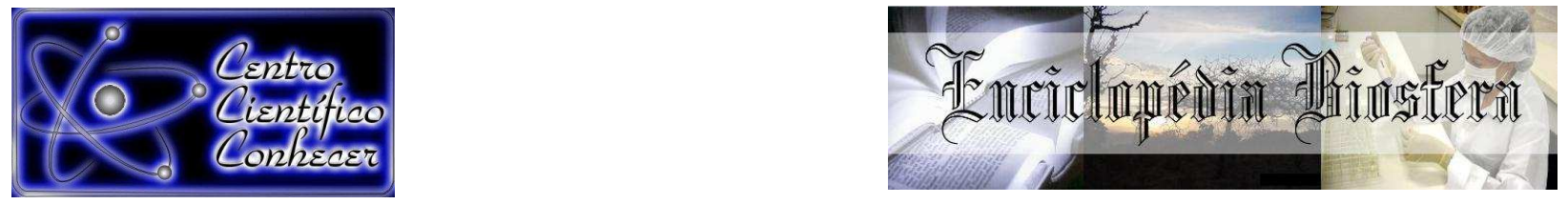

\title{
MANEJO ALTERNATIVO DE PLANTAS INVASORAS NO SUDESTE PARAENSE
}

Gleidson Marques Pereira1; Gabriela Pardinho Oliveira²; Savannah Tâmara Lemos da Costa $^{3}$

1 Mestre em Agronomia. Universidade do Estado do Pará.

(agro_gleidson@yahoo.com.br)

2 Graduanda de Engenharia Ambiental. Universidade do Estado do Pará. Campus VIII. Marabá.

3 Graduanda de Engenharia Ambiental. Universidade do Estado do Pará. Campus VIII. Marabá.

Recebido em: 02/10/2017 - Aprovado em: 21/11/2017 - Publicado em: 05/12/2017 DOI: 10.18677/EnciBio_2017B40

\begin{abstract}
RESUMO
Plantas invasoras são todas as espécies de plantas exóticas em dado ecossistema, por interferir negativamente na produção de determinado cultivo comercial, são muito conhecidas também como "ervas-daninhas". O objetivo do presente estudo, foi avaliar a eficiência do feijão-de-porco (Canavalia ensiformes) no controle de agressividade de plantas invasoras em um plantio de maracujá de uma propriedade onde se desenvolve a agricultura familiar, no sudeste paraense. Para isto, utilizou-se o delineamento experimental de blocos ao acaso, com seis repetições e os seguintes tratamentos: (T0) Testemunha; (T1) Feijão-de-porco (Canavalia ensiformes), (T2) Roçagem manual e (T3) Capina. Cada uma com 3,00 x 7,00 m, em um total de 24 parcelas. Além disto, foram efetuados um levantamento florístico da área e as plantas daninhas identificadas utilizando-se um quadrado de madeira de $0,60 \times 0,60 \mathrm{~m}$, arremessado 20 vezes ao acaso sobre linhas transversais em formato de X. A partir disto, observou-se uma grande variação de plantas invasoras no cultivo agrícola, no qual houve predominância de Gramínea (Digitaria ciliares). Os dados indicaram ainda que o tratamento com feijão-de-porco foi o mais eficiente no controle das plantas invasoras $(63,86 \%)$, enquanto que a roçagem manual e a capina não diferiram significativamente. Já para a quantidade de frutos por parcela, nenhum dos tratamentos apresentou diferença significativa. Dessa forma, mesmo sem contribuir com o aumento na produtividade do plantio de maracujá, notou-se que o feijão-de-porco apresentou eficiência na inibição do desenvolvimento de plantas invasoras.
\end{abstract}

PALAVRAS-CHAVE: Cultivo comercial. Manejo. Plantas daninhas.

\section{ALTERNATIVE MANAGEMENT OF INVASIVE PLANTS IN THE SOUTHEAST PARAENSE}

\begin{abstract}
Invasive plants are all species of plants rejected in a given ecosystem, because they negatively interfere in the production of a particular commercial crop, they are also
\end{abstract}


well-known like "weeds". The objective of the present study was to evaluate the efficiency of the Canavalia ensiformes in the control of aggressiveness of invasive plants in a passion fruit plantation of a property where family farming is developed in southeastern Pará. For this, the experimental design of randomized blocks was used, with six replicates and the following treatments: (T0) Witness; (T1) Pig Bean (Canavalia ensiformes), (T2) Manual trimming and (T3) clear off. Each with $3.00 \mathrm{x}$ $7.00 \mathrm{~m}$, in a total of 24 plots. In addition, a floristic survey of the area and identified weeds were performed using a wooden square of $0.60 \times 0.60 \mathrm{~m}$, thrown 20 times at random on X-shaped transverse lines. From this, a large variation of invasive plants was observed in the agricultural crop, in which there was predominance of Graminea (Digitaria ciliares). The data also indicated that treatment with Pig Bean was the most efficient in the control of invasive plants (63.86\%), while manual cutting and weeding did not differ significantly. As for the amount of fruits per plot, none of the treatments presented a significant difference. Thus, even without contributing to the increase in the productivity of passion fruit planting, it was observed that the Pig Bean had satisfactory results in inhibiting the development of invasive plants.

KEYWORDS: Commercial cultivation. Weed. Management.

\section{INTRODUÇÃO}

O Brasil enquadra-se mundialmente como o maior produtor e consumidor de maracujá. Sua produção por ano é de aproximadamente 1 milhão de toneladas. Em 2015, o Estado do Pará alcançou o total de 33.154 toneladas. Nessa perspectiva, o cultivo desta fruta é uma alternativa à geração de renda, principalmente, na agricultura familiar, e várias tecnologias tem sido desenvolvidas a fim de melhorar o sistema de produção (FALEIRO et al., 2016).

Nesse contexto, a necessidade de desenvolver pesquisas para formas de manejo de plantas invasoras, encontradas em diversos sistemas produtivos, foi notada apenas em 1958, por Charles Elton em seu livro Ecology of invasions by animals and plants. Define-se plantas invasoras como sendo espécies exóticas que crescem e se reproduzem de maneira rápida e intensa em meio ao ecossistema natural ou antrópico, modificando sua composição ou estrutura. É muito conhecida também como "ervas-daninhas" e entre os agricultores são uma espécie de praga agrícola. Umas das causas do aparecimento de plantas invasoras em cultivos agrícolas é decorrente da fertilização do solo, alterações microclimáticas ou a própria eliminação de plantas indesejadas por parte do agricultor, tornando o ambiente propício à outras (PAES, 2016).

Vale ressaltar que este conceito está associado ao aparecimento de determinada espécie exótica, e que, portanto, pode ser invasora em certos momentos, se estiver interferindo negativamente na produção, porém, pode não ser classificada dessa maneira em outra situação. Dessa forma, uma espécie só deve ser considerada daninha ou invasora quando estiver interferindo no desenvolvimento de culturas comerciais, tal como o maracujá (CARVALHO, 2013).

Nessa perspectiva, as gramíneas são uma família de plantas, na qual, em grande quantidade, tornam-se invasoras e competem com espécies nativas por água, nutrientes e luz. Em relação a este último aspecto, as gramíneas formam uma densa camada de biomassa, o que dificulta a penetração de luminosidade na superfície do solo, assim, impedem o crescimento de outras espécies autóctones. 
Além da ameaça à biodiversidade e o excesso de biomassa propicia a ocorrência de incêndios em virtude de sua inflamabilidade (HOROWITZ et al., 2013).

Outras consequências decorrentes do aparecimento de plantas invasoras em áreas de cultivo referem-se à perda de eficiência na produtividade, pois a mesma é reduzida e se torna mais cara em decorrência dos gastos com controle, além disto, há uma perda na qualidade do produto e, consequentemente, seu preço de mercado diminui (BONALDI; HASSE, 2016).

Dessa forma, existem diversos métodos aplicados ao controle de plantas invasoras, sendo alguns deles o controle biológico com a introdução de organismos vivos como agentes biocontroladores; a utilização de cobertura morta ou adubação verde na superfície do plantio e; a rotação de culturas. Estas técnicas são eficientes no combate a ervas daninhas pois proporcionam um conjunto de ações com efeitos físicos, químicos e biológicos como por exemplo, a alelopatia e impedimento de passagem de luz para sementes das espécies exóticas (MARTINS et al., 2016; GALON et al., 2016; SOARES et al., 2015).

Diante dos aspectos apresentados, o objetivo deste trabalho foi avaliar a eficiência do feijão-de-porco (Canavalia ensiformes) no controle da agressividade de plantas invasoras em um plantio de maracujá no sudeste paraense.

\section{Área de coleta}

\section{MATERIAL E MÉTODOS}

O experimento foi realizado, em um plantio de maracujá de dezoito meses de idade, na propriedade de um agricultor familiar (Coordenadas da propriedade Long.: $665169.00 \mathrm{~m} \mathrm{E}$, e Lat.: $9347621.00 \mathrm{~m} \mathrm{~S}$ ) pertencente ao projeto de assentamento Ipiranga, no qual desenvolve o agroecossitemas como modelo agrícola de cultivo. A propriedade está localizada a $38 \mathrm{Km}$ da sede do município de Curionópolis-PA (Figura 1).

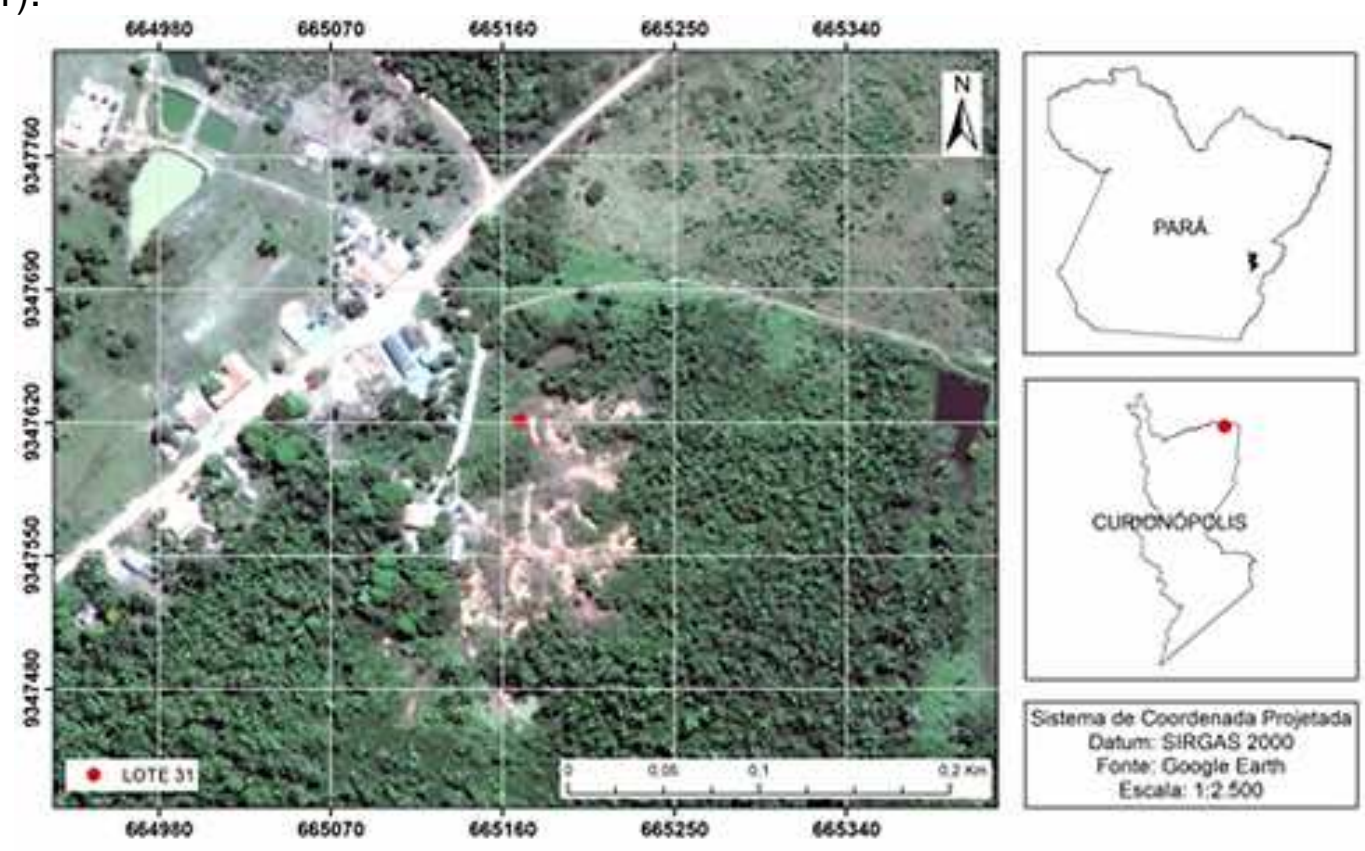

FIGURA 1 - Localização da área de estudo. Projeto de assentamento Ipiranga, CurionópolisPA. Fonte: Autores. 
O delineamento experimental foi de blocos ao acaso, com seis repetições e os seguintes tratamentos: (T0) testemunha, sem capina ou roçagem, (T1) Feijão-deporco (Canavalia ensiformes), (T2) Roçagem manual e (T3) Capina. Cada parcela experimental mediu 3,00 x 7,00 m, em um total de 24 parcelas espaçadas entre si por ruas de $3,00 \mathrm{~m}$, perfazendo uma área total de $504 \mathrm{~m}^{2}$. Nas parcelas utilizadas com o tratamento T1 (feijão-de-porco), realizou-se 0 plantio usando um espaçamento de $1,00 \times 0,50 \mathrm{~m}$, resultando em 4 linhas de plantio e perfazendo um total de 60 covas por parcela, nas quais foram semeadas duas sementes em cada.

Nas demais parcelas, utilizadas para os tratamentos T2 (roçagem manual) e T3 (capina), receberam respectivamente, roçagens manuais e capinas, bimestrais. Antes da instalação do experimento, foram efetuados um levantamento florístico da área, a fim de se conhecer as espécies invasoras dominantes na mesma.

\section{Amostragem}

A amostragem das plantas daninhas foi feita baseada no método descrito por Velini (1997). Em cada local de coleta, foi selecionada uma área de cerca de 1 ha, onde foram demarcadas duas linhas transversais, em formato de $X$, e na qual foram feitas as coletas utilizando-se de um quadrado de madeira de 0,60 x 0,60m, arremessado 20 vezes ao acaso sobre as linhas, totalizando 20 amostras por área de coleta. A cada arremesso, as plantas que estavam dentro do quadrado foram cortadas rente ao solo, acondicionadas em sacos plásticos e transportadas para 0 Laboratório de Botânica da Universidade Federal Rural da Amazônia (UFRA), onde foram quantificadas e identificadas para os estudos seguintes.

As avaliações da porcentagem de infestação de plantas invasoras, nas parcelas experimentais aos 90, 120 e 180 dias pós-germinação, foram feitas através do método visual de Furtick e Romanowski, que consiste em lançar, em cinco pontos diferentes na parcela, um quadro de madeira de $0,25 \mathrm{~m}^{2}(0,50 \times 0,50 \mathrm{~m})$, efetuou-se as observações da porcentagem da área do quadro que foi preenchida. Os cálculos da eficiência de controle foram feitos pelo método de Schneider e Orelli (Nakano et al., 1981) e analisados pelo software estatístico $R$. As observações sobre a possível contribuição nutricional do feijão-de-porco sob a produção de maracujá, foram feitas através de contagem do número de frutos.

\section{Identificação das plantas invasoras coletadas}

Para identificação das espécies, foram retiradas amostras de cada planta, prensadas e colocadas para secar em estufa a $75^{\circ} \mathrm{C}$, durante 48 horas. Depois, montadas em exsicatas e identificadas por classe, família, gênero e espécie (Kissmann; Groth, 1997; Lorenzi, 1994). Após a identificação, foi calculada a frequência das espécies, de acordo com Brandão et al. (1998), em que frequência é igual ao $\mathrm{n}^{0}$ de amostras que contêm a espécie, dividida pelo $\mathrm{n}^{\circ}$ total de amostras obtidas.

\section{RESULTADOS E DISCUSSÃO}

Nos resultados observados (Tabela 1 ), verifica-se que em relação ao parâmetro eficiência de controle de plantas daninhas, houve diferenças significativas entre os tratamentos, sendo que o tratamento $\mathrm{T} 1$ foi o que demonstrou maior eficiência entre os demais $(63,86 \%)$. 
TABELA 1 - Resultados da porcentagem de eficiência de controle de plantas invasoras.

\begin{tabular}{cc}
\hline Tratamentos & $\begin{array}{c}\text { Média } \% \text { - eficiência de controle } \\
\text { matovegetação }\end{array}$ \\
\hline T0 - testemunha & $0 \mathrm{a}$ \\
T1 - feijão-de-porco & $63,86 \mathrm{~b}$ \\
T2 - roçagem & $18,65 \mathrm{c}$ \\
T3 - capina & $22,17 \mathrm{c}$ \\
\hline
\end{tabular}

Medias seguidas da mesma letra não diferem significativamente ao teste de Tukey a $5 \%$ de probabilidade.

Este resultado diferiu do obtido por Soares et al., (2015) em estudo realizado no estado de Mato Grosso. Para os autores, o feijão-de-porco (Canavalia ensiformes) possui baixa capacidade em suprimir o crescimento de plantas invasoras, já que no estudo, esta espécie apresentou desenvolvimento inicial muito lento, permitindo melhores condições para o aparecimento de plantas indesejadas. Do mesmo modo, Lima et al., (2014) no estado de Goiás constatou pouca eficácia na supressão do crescimento de espécies invasoras.

No entanto, em Capitão Poço, no nordeste do estado do Pará, Saldanha et al., (2017) verificaram que o feijão-de-porco, reduziu a incidência de plantas invasoras, já que diminuiu a erosão do solo e manteve a umidade adequada, ou seja, contribuiu para a conservação do solo.

Da mesma forma, em Coimbra-MG, os autores Correa et al., (2014) verificam que a Canavalia ensiformes, quando em consórcio com o milho é capaz de realizar a função de controle, em virtude de seu efeito alelopático. Os autores atribuem ao feijão-de-corpo os benefícios de aumento na produção de grãos, diminuição da população de sementes de espécies invasoras e aumento no aporte de nitrogênio. A análise dos dados obtidos em Curionópolis corrobora com as afirmativas dos benefícios do feijão-de-corpo, visto que observou-se eficiência bem superior as demais técnicas de tratamento.

Com relação a roçagem, os autores Hirata et al., (2014), com estudo no município de Álvares Machado-SP em plantio de hortaliças, relataram que nas áreas de manejo que foram roçadas, houve o maior acumulo de massa de plantas invasoras, já que após o corte voltavam a crescer. A ineficiência da roçagem para controle dessas espécies indesejadas também foi percebida neste estudo, onde apresentou eficiência de $18,65 \%$. Além disto, este tipo de tratamento ainda apresenta inviabilidade técnica, visto que há o emprego de mão-de-obra pesada para constante manutenção da área manejada.

Apesar de apresentar eficiência de $22,17 \%$, pouco maior que a roçagem, os resultados para capina não diferiram significativamente desta. Silva et al., (2012) demonstraram que a capina também favorece uma nova infestação de plantas invasoras após a retirada, o que compromete a eficiência de controle deste tratamento. Ainda assim, segundo os autores, a capina é um dos métodos de manejo mais utilizado para alguns cultivos. Desse modo, entre os tratamentos analisados, o que permitiu melhor eficiência no controle a plantas invasoras, elevando a qualidade no plantio, foi com o emprego do feijão-de-porco.

Quanto aos resultados das espécies florísticas identificadas (Tabela 2), demonstraram uma grande variedade de plantas invasoras no sistema produtivo do agricultor, sendo que a Gramínea (Digitaria ciliaris) apresentou infestação predominante na área (30\%). 
TABELA 2- Resultados do levantamento florístico das espécies identificadas.

\begin{tabular}{ccc}
\hline Espécie & Nome Vulgar & \% Infestação \\
\hline Digitaria ciliares & Gramínea & 30 \\
Commelina virginica & Maria mole & 18 \\
Borreria verticilata & Vassourinha de botão & 15 \\
Portulaca oleraceae & Beldroega & 15 \\
Sida $s p$. & Malva & 10 \\
Outras & Outras & 12 \\
\hline
\end{tabular}

A variação das espécies de plantas invasoras encontradas pode ser explicada pelas diferentes formas de manejo usadas em cada sistema de produção. Erasmo et al., (2004) em estudo realizado nas áreas de produção de arroz irrigado na região de Formoso do Araguaia-TO, observaram grande variação de espécies em propriedades de pequenos e grandes produtores. $O$ mesmo foi observado por Nagahama et al., (2014) que quantificaram a existência de cinco espécies invasoras em plantio de sorgo forrageiro com base em pesquisa na cidade de Petrolina-PE. Em Curionópolis, a quantidade de espécies encontradas vai em consonância com a diversidade descrita pelos autores, o que demonstra a resistência de plantas daninhas em sistemas produtivos.

No local de estudo, a infestação no cultivo, pode estar associado a escassez de mão de obra para serviços de capina, que são agravados pelas condições climáticas da região, em que há intensa radiação solar. Além do mais, atividades de manejo, tais como roçagem e capina encarecem a produção, tornando-se inviável ao pequeno agricultor familiar.

Já os dados obtidos com relação ao número de frutos por parcela, indicaram que os tratamentos não interferiram significativamente na produtividade do maracujazeiro e não diferiram significativamente entre si (Tabela 3). Apesar disto, a variabilidade dos dados por meio do coeficiente de variação situou-se em $23 \%$. Gomes (1990), considera alto entre 20 e 30\%, valores esses obtidos em experimentos de campo com culturas agrícolas.

TABELA 3 - resultados da avaliação do número de frutos por parcela.

\begin{tabular}{cc}
\hline Tratamentos & Média $-\mathbf{n}^{\circ}$ de fruto / parcela \\
\hline T0 - testemunha & $7,67 \mathrm{~ns}$ \\
T1 - feijão-de-porco & $13,32 \mathrm{~ns}$ \\
T2 - roçagem & $8,93 \mathrm{~ns}$ \\
T3 - capina & $7,68 \mathrm{~ns}$ \\
\hline
\end{tabular}

$\overline{\text { Medias seguidas de ns não diferem significativamente ao teste de } \mathrm{F} \text { a } 5 \% \text { e a } 1 \% \text { de probabilidade. }}$

Em estudo no município de Uberlândia-MG, Melo Júnior et al., (2012) apontaram que as características produtivas do maracujazeiro em relação ao número de frutos são influenciadas, principalmente, pela altura da espaldeira e pela distância entre as linhas de plantio, devido contribuir para a diminuição dos efeitos do sombreamento das folhas, aspecto que não foi observado no presente estudo. Constatando-se apenas a inexistência de relação entre os tratamentos empregados para controle das plantas invasoras e o aumento significativo da produtividade.

Por outro âmbito, Brito et al., (2017) demonstraram a capacidade do feijão-deporco em favorecer a produtividade do milho quando utilizado como adubo verde no estado de Mato Grosso do Sul, por realizar o aporte de nutrientes como o nitrogênio e o cálcio. Todavia, na propriedade do agricultor familiar, não foi notado o acréscimo de nutrientes como citado pelos autores. 


\section{CONCLUSÃO}

No sudeste paraense, o feijão-de-porco como tratamento no controle de plantas invasoras, apresentou-se viável em relação as formas de manejo com capina e roçagem, já que apontou eficiência de $63,86 \%$. Além disto, tanto a capina como a roçagem ocasionam problemas com o surgimento de novas infestações de espécies indesejadas, o que torna o manejo com Canavalia ensiformes, uma melhor opção tecnicamente.

No entanto, nenhum dos tratamentos empregados foi capaz de influenciar na quantidade de frutos por parcela do maracujazeiro, elevando a produção. Apesar disto, o emprego do feijão-de-porco não encarece a produção como o faz atividades de capina e roçagem, pela necessidade de constante utilização de mão-de-obra.

\section{REFERÊNCIAS}

BRANDÃO, M.; BRANDÃO, H.; LACA-BUENDIA, J. P. A mata ciliar do Rio Sapucaí, município de Santa Rita do Sapucaí-MG: fitossociologia. Daphne, v. 8, n. 4, p. 36-48, 1998.

BRITO, M. F.; TSUJIGUSHI, B. P.; ROCHA, D. P.; SILVA, R. F. Reciclagem de nutrientes de adubos verdes e produtividade de milho cultivado em sucessão em agroecossistema de transição agroecológica. Acta Iguazu, v. 6, n. 3, p. 11-21, 2017. Disponível em:

$<\mathrm{e}-$ revista.unioeste.br/index.php/actaiguazu/article/download/17669/11725>.

BONALDI, R. A.; HASSE, I. Flora arbórea da arborização urbana da cidade de Paranaguá, Paraná, Brasil. Revista Sociedade Brasileira de Arborização Urbana, v. $11, \quad$ n. $4, \quad$ p. $01-17,2016$. Disponível em: $<$ http://www.revsbau.esalq.usp.br/teste/ojs-

2.3.7/index.php/REVSBAU/article/view/599>.

CARVALHO, L. B. Plantas Daninhas. Lages, SC: Edição do autor, 2013. 82p.

CORREA, M. L. P.; GALVÃO, J. C. C.; FONTANETTI, A.; LEMOS, J. P.; CONCEIÇÃO, P. M. Interferência do feijão-de-porco na dinâmica de plantas espontâneas no cultivo do milho orgânico em sistemas de plantio direto e convencional. Revista Brasileira de Agroecologia, v. 9, n. 2, p. 160-172, 2014. Disponível em:

http://orgprints.org/27388/1/Correa_Interfer\%C3\%AAncia\%20do\%20feij\%C3\%A30\% 20de\%20porco\%20na\%20din\%C3\%A3mica.pdf>.

ERASMO, E. A. L.; PINHEIRO, L.L.A.; COSTA, N.V. Levantamento Fitossociológico das comunidades de plantas infestantes em áreas de produção de arroz irrigado cultivado sob diferentes sistemas de manejo. Planta Daninha, v. 22, n. 2, p. 195201, $2004 . \quad$ Disponível em:< http://www.scielo.br/scielo.php?script=sci_arttext\&pid=S0100-83582004000200004 >. DOI: http://dx.doi.org/10.1590/S0100-83582004000200004.

FALEIRO, F. G. Maracujá: o produtor pergunta, a Embrapa responde. Brasília, DF: Embrapa, 2016. 341p. 
GALON, L.; MOSSI, A. J.; REICHERT JUNIOR, F. W.; REIK, G. G.; TREICHEL, H.; FORTE, C. T. Biological weed management - A short review. Revista Brasileira de Herbicida, v. 15, n. 1, p. 116-125, 2016. Disponível em: <http://www.rbherbicidas.com.br/index.php/rbh/article/view/452/452>. DOI: https://doi.org/10.7824/rbh.v15i1.452.

GOMES, F.P. Curso de estatística experimental. 12.ed. São Paulo: Nobel, 1990. $467 p$.

HIRATA, A. C. S.; HIRATA, E. K.; GUIMARÃES, E. C.; RÓS, A. B.; MONQUERO, P. A. Plantio direto de alface americana sobre plantas de cobertura dessecadas ou roçadas. Solos e nutrição de plantas, v. 73, n. 2, p. 178-183, 2014. Disponível em:< http://www.scielo.br/scielo.php?script=sci_arttext\&pid=S0006$87052014000200013 \& \operatorname{lng}=\mathrm{pt} \&$ tlng $=\mathrm{pt}>$. http://dx.doi.org/10.1590/brag.2014.024.

HOROWITZ, C.; OLIVEIRA, A. S.; SILVA, V.; PACHECO, G.; SOBRINHO, R. I. Manejo da flora exótica invasora no Parque Nacional de Brasília: contexto histórico e atual. Biodiversidade Brasileira, v. 3, n. 2, p. 217-236, 2013. Disponível em: <http://www.icmbio.gov.br/revistaeletronica/index.php/BioBR/article/view/354>.

KISSMANN, K. G.; GROTH, D. Plantas infestantes e nocivas. 2.ed. São Paulo: BASF Brasileira, 1997. Tomo 1. 25 p.

LIMA, S. F.; TIMOSSI, P. C.; ALMEIDA, D. P.; SILVA, U. R. Fitossociologia de plantas daninhas em convivência com plantas de cobertura. Revista Caatinga, v. 27, n. 2, p. 37-47, 2014. Disponível em: < http://www.redalyc.org/pdf/2371/237131344005.pdf>.

LORENZI, H. Manual de identificação e controle de plantas daninhas: plantio direto e convencional. 4.ed. Nova Odessa: Plantarum, 1994. 299 p.

MARTINS, D.; GONÇALVES, C. G.; SILVA JÚNIOR, A. C. Coberturas mortas de inverno e controle químico sobre plantas daninhas na cultura do milho. Revista Ciência Agronômica, v. 47, n. 4, p. 649-657, 2016. Disponível em: < http://www.scielo.br/pdf/rca/v47n4/1806-6690-rca-47-04-0649.pdf>. http://dx.doi.org/10.5935/1806-6690.20160078.

MELO JÚNIOR, H. B.; ALVES, P. R. B.; MELO, B.; DUARTE, I. N.; TEIXEIRA, L. M. Produção do maracujazeiro amarelo sob diferentes sistemas de condução. Enciclopédia Biosfera, centro científico conhecer, v. 8, n. 15, p. 1412-1422, 2012. Disponível em: http://www.conhecer.org.br/enciclop/2012b/ciencias\%20agrarias/producao\%20do\%2 Omaracujazeiro.pdf>.

NAGAHAMA, H.J.; CORTEZ, J.W.; CONCENÇO, G.; ARAUJO, V.F.; HONORATO, A.C. Dinâmica e variabilidade espacial de plantas daninhas em sistemas de mobilização do solo em sorgo forrageiro. Planta daninha, v. 32, n. 2, 2014. 
Disponível em: <http://www.scielo.br/scielo.php?script=sci_arttext\&pid=S010083582014000200003>. DOI: http://dx.doi.org/10.1590/S0100-83582014000200003.

NAKANO, O.; SILVEIRA NETO, S.; ZUCCHI, R. A. Entomologia Econômica. São Paulo: Livroceres, 1981. 314 p.

PAES, M. P. Plantas exóticas invasoras no Brasil: uma ameaça às plantas nativas e ao ecossistema. Revista Especialize, v. 1, n. 11, p. 1-14, 2016. Disponível em: < https://www.ipog.edu.br/download-arquivo-site.sp?arquivo=magda-passos-paes10121812.pdf>.

SALDANHA, E. C. M.; SILVA JÚNIOR, ALVES, J. D N.; MARIANO, D. C.; OKUMURA, R. S. Consórcio milho e feijão-de-porco adubado com NPK no nordeste do Pará. GI. Science Technology v. 10, n. 01, p. 20-28, 2017. Disponível em: < https://rv.ifgoiano.edu.br/periodicos/index.php/gst/article/view/846>.

SILVA, D. V.; SANTOS, J.B.; FERREIRA, E.A.; SILVA, A.A.; FRANÇA, A.C.; SEDIYAMA, T. Manejo de plantas daninhas na cultura da mandioca. Planta Daninha, v. 30, n. 4, p. 901-910, 2012. Disponível em: $<$ http://www.scielo.br/scielo.php?script=sci_arttext\&pid=S010083582012000400025> DOI: http://dx.doi.org/10.1590/S0100-83582012000400025.

SOARES, C. M. J.; RAMBO, J. R.; CAVALLARI, A. P.; OLIVEIRA, M. S.; SOARES, D. M. J. S. Produção de adubos verdes no cerrado e seus efeitos sobre as plantas daninhas. Revista de Ciências Agroambientais, v. 13, n. 12, p. 57-64, 2015. Disponível em: <https://periodicos.unemat.br/index.php/rcaa/article/view/1184/1258>.

VELINI ED. 1997. Interferências entre plantas daninhas e cultivadas. In: SIMPÓSIO SOBRE HERBICIDAS E PLANTS DANINHAS, 1, Dourados. Resumos... Dourados: Embrapa CPAO. p.29-49. (Embrapa CPAO, Documentos, 13). 